\title{
Use of operative laparoscopy in single incision and natural orifice transvaginal surgery
}

To the Editor,

I read with interest the article titled "Single-incision-two port laparoscopic tubal ligation: A cost comparison and technique description" by Drs Nicel Taşdemir, Remzi Abali, Cem Çelik, Erson Aksu, and Didem Akkuş. J Turk Ger Gynecol Assoc 2015; 16: 30-1 that was published online on March 1, 2015 (1). The authors compare the traditional 2-port laparoscopy with a single incision using two $5 \mathrm{~mm}$ trocars. We had a different experience while using a laparoscope with an operative channel to place a bipolar cautery in tubal ligations; thus, limiting to a one-port laparoscopy. Furthermore, we used a laparoscope with a 6-mm operative channel to place different instruments in single incision (2) and in natural orifice transvaginal cholecystectomies (3). The operative laparoscope is not a new instrument; however, it should not be disregarded and is probably still utilized in many hospitals. It is my opinion that revisiting laparoscopy techniques using this operative laparoscope could further enhance the concepts of minimally invasive surgery.

\section{Daniel Tsin}

Department of Gynecology, Division of Natural Orifice Surgery, New European Surgical Academy, Berlin, Germany

\section{References}

1. Taşdemir N, Abali R, Çelik C, Aksu E, Akkuş D. Single-incisiontwo port laparoscopic tubal ligation: A cost comparison and technique description. J Turk Ger Gynecol Assoc 2015; 16: 30-1. [CrossRef]

2. Tsin DA, Davila F, Dominguez G, Manolas P. Secured independent tools in peritoneoscopy. JSLS 2010; 14: 256-8. [CrossRef]

3. Davila F, Tsin DA, Dominguez G, Davila U, Jesús R, Gomez de Arteche A. Transvaginal cholecystectomy without abdominal ports. JSLS 2009; 13: 213-6.
Author's Response

We thank the authors for their valuable comments on our study. Minimally invasive surgery has come to the fore in many areas (1-3). Many minimally invasive surgical techniques have been developed; therefore, many different techniques for this type of surgery are available (4). The most important limitation of minimally invasive surgery is cost. Single-port laparoscopy also involves additional costs. With the techniques that we described, material costs decreased approximately six times (from 365 Euros to 66 Euros) (5). The aim of this article was to show that we can perform minimally invasive surgery at a lower cost. We agree that revisiting laparoscopic techniques using operative laparoscopes could further enhance the concept of minimally invasive surgery. We hope that this technique and the authors' suggestions would lead to an increase in the use of minimally invasive surgery.

\section{Nicel Taşdemir}

Department of Obstetrics and Gynecology, Namık Kemal University Faculty of Medicine, Tekirdağ, Turkey

\section{References}

1. Pandis GK, Michala L, Creighton SM, Cutner AS. Minimal access surgery in adolescent gynaecology. BJOG 2009 Jan; 116: 214-9. [CrossRef]

2. Steiner RA, Fehr PM. Minimal invasive surgery in gynaecology. Ther Umsch 2005; 62: 127-38. [CrossRef]

3. Solà Dalenz V, Pardo Schanz J, Ricci Arriola P, Guiloff Fische E, Chiang Miranda H. Minimal invasive surgery in female urinary incontinence: TVT-O. Actas Urol Esp 2006; 30: 61-6. [CrossRef]

4. Davila F, Tsin DA, Dominguez G, Davila U, Jesús R, Gomez de Arteche A. Transvaginal cholecystectomy without abdominal ports. JSLS 2009; 13: 213-6.

5. Tasdemir N, Abali R, Celik C, Aksu E, Akkus D. Single-incisiontwo port laparoscopic tubal ligation: A cost comparison and technique description. J Turk Ger Gynecol Assoc 2015; 16: 30-1. [CrossRef] 